\title{
Second language development in the context of massively multiplayer online games: Theoretical perspectives
}

\author{
Nasser Jabbari
}

\section{Introduction}

The potential of massively multiplayer online games (MMOGs) for second language (L2) learning has widely been investigated. However, the research in this area lacks rigor in terms of the variety and precision of theoretical frameworks (from second language acquisition (SLA) or related fields like psychology, sociology and anthropology) that can lead the design of the research projects, frame their research questions and be drawn upon to interpret data (Jabbari and Eslami 2019). Researching L2 learning in the context of MMOGs is untenable unless L2 development is conceptualized as the outcome of the interplay between two macro-systems, that is, the learner and the game, each comprising interrelated and interdependent micro-systems or components. Godwin-Jones (2014: 12) highlighted, 'Particularly helpful would be studies that seek to identify what particular user behaviors, game elements, and game resources seem to be the most promising for language learning.' Accordingly, the main question would be: What learner and game-related variables interact to determine L2 development through MMOG play? To answer this question, researchers need to draw on different theories to explain, predict or formulate some propositions about the optimal conditions (e.g. cognitive, social and affective) that MMOGs can afford for L2 development to take place.

Much of the research that examined one or more aspect(s) of L2 development in the contexts of video games including MMOGs lacks a sound theoretical grounding (Jabbari and Eslami 2019) or is not based on theories of learning (Ke 2009; Wu et al. 2012; Whitton 2014). For example, Wu and colleagues (2012) 
found that only 91 of 567 (16 per cent) game-assisted learning research studies based their investigations in learning theory. Similarly, Jabbari and Eslami (2019) found that ten of thirty-one (32 per cent) studies did not even refer to a single theoretical or conceptual framework. As they reported, among those studies with some theoretical frameworks, Vygotsky's (1978) sociocultural theory (SCT) was the most frequently cited theory but without its principles and constructs determining the research questions, hypotheses or methodologies. There are several theories - originated in different disciplines (e.g., education, sociology, psychology, and anthropology) - that can be woven together to provide a comprehensive foundation upon which different aspects (e.g. cognitive, social and affective) of L2 development in the context of MMOGs can be characterized. A theoretical orientation frames the boundaries of a research study and provides a lens through which the phenomenon under investigation can be explained by first defining the key constructs at play and then establishing the relationships among them. In other words, theory in research determines the most paramount elements of a research study including the research question, the research paradigm (i.e. qualitative or quantitative), the methods or techniques for collecting and analysing data and the lens through which to interpret findings (Reinhardt 2019). Neuman (2003: 65) highlighted the role of theory in research, stating,

Theory frames how we look at and think about a topic. It gives us concepts, provides basic assumptions, directs us to the important questions, and suggests ways for us to make sense of data. Theory enables us to connect a single study to the immense base of knowledge to which other researchers contribute. To use an analogy, theory helps a researcher see the forest instead of just a single tree.

SLA researchers need well-founded theoretical assumptions to underlie the hypotheses they formulate and the research methodologies they adopt to inquire about particular aspects of L2 learning and socialization through the medium of MMOGs. Therefore, providing a detailed outline and discussion of some relevant theories may enhance the quality of research in this area. This chapter is a small contribution to achieve this goal. To do so, it first describes the context of MMOGs, which has been theorized and investigated by SLA scholars as a potentially ideal setting for L2 development (e.g. Peterson 2010a, 2010b; Bytheway 2014; Reinders and Wattana 2015). Then, a brief overview of Egbert, Chao and Hanson-Smith's (1999) conditions for optimal language learning environment is presented to provide a basis for the examination of similar conditions in the context of MMOGs. The rest of the chapter discusses some 
of these conditions in the context of MMOGs by drawing on the underlying constructs of SCT (Vygotsky 1978) as the main theoretical framework. These discussions are expanded by providing relevant links between the key constructs in SCT and some related theoretical constructs underlying Long's (1981) Interaction Hypothesis and Lave and Wenger's (1991) Situated Learning Model. This chapter seeks to help researchers construct more theory-driven research questions and design their research studies accordingly. It also aims at providing language educators with insights into some relevant theoretical and conceptual frameworks that rationalize the incorporation of MMOG-mediated activities in L2 teaching and learning practices.

\section{The context of MMOGs}

Before learning about relevant theories that can inform this area of research, it is necessary to know the context in which L2 development is theorized and discussed. The focus of this paper is theorizing L2 development in the context of commercially designed off-the-shelf (COTS) MMOGs, which are not designed for educational purposes. Like any other forms of online social media (Kaplan and Haenlein 2010), COTS MMOGs are designed to serve entertainment purposes. These games are played by thousands of players located in different parts of the world. The game players can interact, cooperate and compete to finally level up their characters in the game world. These games, which contain elements of fantasy and science fiction, provide dynamic virtual worlds in highly visually appealing 3D environments. Before entering the game world, players choose the realm (e.g. player versus environment, player versus player) they want to play in, choose and customize their in-game characters (known as avatars) by choosing their race, class, gender and appearance. The gameplay is mostly about gaining rewards and achieving higher levels in the game through completion of various types of quests (or missions), which are assigned by the characters controlled by the game known as non-playing characters (NPCs). Quests involve one or more interrelated activities such as attacking certain enemies or structures, slaying monsters, gathering resources, finding and delivering items. Players have the discretion to complete quests independently; however, as the game progresses, quests grow more challenging warranting collaboration and coordination among players. Players face quite formidable challenges in dungeons (for instance). A typical dungeon (made available around level 15) allows a group of five players to enter. Some dungeons (made 
available around level 60), however, require more players (e.g. ten, twenty-five or forty) to collaborate in a 'raid' to complete quests. Therefore, players have to form persistent groups (technically known as guilds) to complete quests and accomplish in-game targets. The medium of communication in MMOGs is primarily synchronous text-based chat. For example, in World of Warcraft, the game provides players with different chat channels technically referred to as 'say', 'yell' and 'whisper'. Each chat channel provides gamers with various levels of privacy in communication. For instance, trade and general chat channels are the most public channels that allow all online members in a gamer's faction to read the message and respond back. Two other examples of chat channels are 'guild' and 'party' that are available only for the members of the online guild and questing party, respectively. 'Whispers' or 'tells', on the other hand, are the most private messages that can be shared only between two gamers. In addition to text chat channels, participants can communicate via third-party voice communication software (e.g. TeamSpeak) or simply use Skype whenever required.

\section{L2 development in the context of MMOGs}

Second language development in the context of commercially developed or 'vernacular' (Reinhardt and Sykes 2012) MMOGs can be conceptualized as a natural phenomenon (or process) that takes place as L2 is used in an authentically contextualized communication setting (Peterson 2012a; Thorne and Fischer 2012) - the setting in which the learner gets involved in meaningful interactions not only with other gamers but also with the game's environment that features multiple meaning-making media (e.g. sounds and voices, shapes and images, movements and actions, texts, colours and objects). In such a semiotically rich (Thorne and Fischer 2012) and linguistically complex (Thorne, Fischer and $\mathrm{Lu}$ 2012) communication environment, the learner undertakes various meaningful, goal-oriented tasks with different utility condition (Loschky and Bley-Vroman 1993) - that is 'the degrees of likelihood that a particular structure will be used by learners as they perform a task' (Chapelle 2001: 46). Accordingly, being involved in performing coherently interrelated tasks to, say, complete quests, the learner is exposed to a level of target language that is sometimes beyond his or her linguistic capacity (Thorne, Fischer and $\mathrm{Lu}$ 2012). By drawing on his/her cognitive capacities and the clues featured by the game's multimodal environment, the L2 learner attempts to 
develop links between form and meaning (in the target language). In such conditions, L2 is utilized - as a powerful medium - for a genuine purpose that is co-construction and communication of meaning in an effective and efficient manner. Second language L2 form, which 'can refer to lexical (both phonological and orthographic), grammatical, and pragmalinguistic features' (Ellis 2016: 408-9), is thus focused on whenever it plays a critical role in the gamers' meaning-making endeavours during the gameplay. For example, L2 form is focused on when it triggers a communication breakdown particularly during critical moments in which failure in communication can jeopardize the gamers' (and their teams') status in the game world. On such occasions, L2 learners and other gamers get actively involved in collaborative meaningmaking activities to finally bridge the communication gap.

In such communicative contexts, L2 learners can also be considered as autonomous agents (Przybylski, Ryan and Rigby 2009) as they can decide about the class, the role, the gender and the outfits of their virtual characters. They can roam around freely and explore the game world independently. Entirely of their own volition, they can choose to collaborate with other game players in a team or proceed with very little, if any, interaction with other game players. They have the luxury of finding their motives in playing the game (e.g. exploration, socialization, achievement, dissociation) and develop their unique playing styles accordingly (Fuster et al. 2014). Adopting different combinations of the alternatives mentioned determines the quality and the quantity of the target language the learner is exposed to and produces in the game environment. Furthermore, SLA scholars who have focused on this area of research are dealing with a social environment wherein participants' (or gamers') common interests, goals, aspirations, motives to play the game or even common worldviews have united them in small or large 'communities of practice' (Wenger 1998).

\section{Conditions for optimal language learning environments}

Spolsky's (1989) general theory of conditions for language acquisition encompasses four macro variables presented in an equation (see Figure 3.1). According to Spolsky, 'abilities' refer to the learner's physiological, biological, intellectual and cognitive skills; and 'opportunity' implies the characteristics of the learning environment (e.g. quality and quantity of exposure to the language in that environment). 


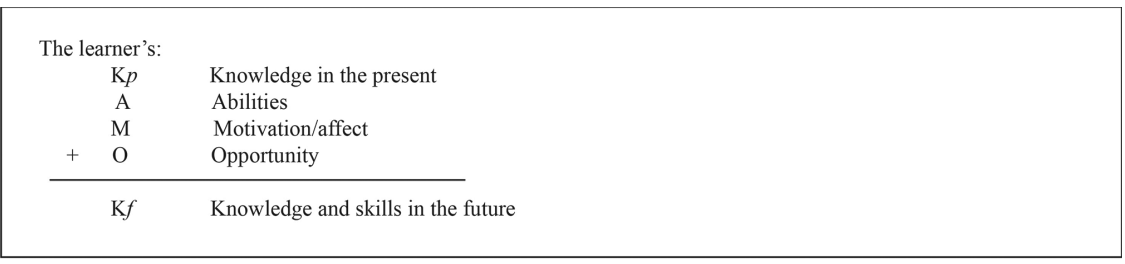

Figure 3.1 Spolsky's (1989) theory of conditions for language acquisition (cited in Egbert, Chao and Hanson-Smith 1999: 2).

Spolsky's equation represents thefact that an optimalinterplayamong cognitive, social and affective variables in a learning environment with well-designed features can provide opportunities for language development. The microanalysis of these variables can lead to a plethora of other significant factors that can play crucial roles in this equation. For example, a learner's current knowledge about a community's social and cultural norms can significantly determine the extent of the learner's later achievements in second language development; or, a learner's 'abilities' to acquire a new language can be affected - either positively or negatively - by other variables such as the learner's current levels of L1 proficiency and the level of divergence (or convergence) of the morphosyntactic and phonological systems of L1 and L2, which can in turn define his/her 'ability' to learn a new language. Similarly, more related variables come into play when the affordances of an environment for providing L2 learning opportunities are taken into scholarly consideration. To name a few, these variables include the amount of L2 exposure, the mode of L2 (i.e. written, spoken or both) and the medium/channel (e.g. face-to-face or computer-mediated) through which a learner is exposed to L2. All these micro-variables can influence the dynamic of the equation proposed by Spolsky. Inspired by Spolsky's theory of conditions for language acquisition, Egbert, Chao and Hanson-Smith (1999: 4) proposed a general model of optimal environmental conditions including: (1) learners have opportunities to interact and negotiate, (2) learners interact in the target language with an authentic audience, (3) learners are involved in authentic tasks, (4) learners are exposed to and encouraged to produce varied and creative language, (5) learners have enough time and feedback, (6) leaners are guided to attend mindfully to the learning process, (7) learners work in an atmosphere with an ideal stress/anxiety level, and (8) learner autonomy is supported. Egbert, Chao and Hanson-Smith (1999) believed that the co-occurrence of these conditions with different degrees and configurations can - contingent upon the learning context - potentially enhance the opportunities for L2 development. 


\section{Sociocultural perspective on L2 development in the context of MMOGs}

The consideration of commercially developed MMOGs as promising venues for L2 development is well grounded in theories of human development (Cornillie, Thorne and Desmet 2012) such as Vygotsky's (1978) social constructivism or SCT. SCT has established itself as 'a vigorous player' (Mitchell, Myles and Marsden 2013) in the area of SLA research. It is also one of the most commonly referenced theoretical frameworks in the study of second language development in the context of MMOGs (Jabbari and Eslami 2019).

In SCT, learning is viewed as primarily social then individual or first interthen intra-mental referred to by Vygotsky (1981) as inner speech. Therefore, according to this theoretical perspective, interactions with individuals and cultural artefacts - in one's physical, social and cultural environment - play a fundamental role in one's cognitive development. In SCT, 'learning is viewed primarily as a social product yielded by the processes of conversation, discussion, and negotiation' (Woo and Reeves 2007: 18). According to Lantolf, Thorne and Poehner (2015: 207), 'SCT argues that while human neurobiology is a necessary condition for higher mental processes, the most important forms of human cognitive activity develop through interaction within social and material environments' (emphasis in original). These interactions are mediated by higher-level symbolic (e.g. language and literacy) and material artefacts/ tools (e.g. computers), which 'serve as a buffer between the person and the environment and act to mediate the relationship between the individual and the social-material world' (Lantolf, Thorne and Poehner 2015: 208). From the sociocultural perspective, the phenomenon of L2 development in the context of MMOGs can be explained by drawing on the key concepts of interaction, mediation, zone of proximal development and regulation.

According to the concept of regulation, which is 'an important form of mediation' (Lantolf, Thorne and Poehner 2015: 209), the locus of control of human activity shifts - in sequentially developed steps - from object- and otherregulation to self-regulation (Lantolf, Thorne and Poehner 2015). Accordingly, one's development in mastering skills is conceptualized as improving one's independence of object- and other-regulation and gradually moving towards self-regulation. In other words, one's proficiency in the use of mediational resources develops as one advances through developmentally sequenced steps starting from an utter reliance (or dependence) on external mediational means (i.e. object- and other-regulation) and moving towards gaining more control 
over one's capacity (i.e. self-regulation) to think and act independently in a social setting (Lantolf, Thorne and Poehner 2015). These principles also apply to the development of L2 skills through active participation in the context of MMOGs. In such contexts, L2 as a higher-level symbolic artefact is accompanied - and mostly supported - by a multitude of material artefacts in the game's virtual environment to mediate L2 gamers' higher-order cognitive activities.

The stage of object-regulation in the process of meaning construction applies when virtual artefacts in the game environment (e.g. non-player characters' actions, maps and the game's various audio and visual elements) and out of this environment (e.g. game-related wikis and fan pages) afford cognition/activity. At this stage of development, L2 gamers rely primarily on the game's multimodal meditational resources (e.g. images, symbols, colours, movements, (inter)actions and sound effects) to construct meaning. Inspired by the concept of 'objectregulation' as the primary stage of development in one's learning process, L2 researchers can, for instance, investigate the quality and the quantity of learnergame interactions to explore the extent to which L2 learners (at different levels of L2 proficiency) rely on the game's non-verbal meditational tools to construct meaning and the extent to which their reliance on the game-mediated tools can contribute to the development of their proficiency (e.g. complexity, accuracy and fluency) and/or communicative skills in the target language.

As Lantolf, Thorne and Poehner (2015: 209) put it, the state of otherregulation 'describes mediation by people and can include explicit or implicit feedback on grammatical form, corrective comments on writing assignments, or guidance from an expert or teacher'. This stage of regulation can be explained by drawing on Jerome Bruner's theory of scaffolding introduced as a part of social constructivist theory. Bruner believed that at the preliminary stages of learning a new concept or acquiring a new skill, children need supports or scaffolding from their parents or other competent adults. These supports diminish gradually as children grow more independent in thinking and acting by drawing on internalized knowledge and skills. Bruner's theory of scaffolding was inspired by Vygotsky's concept of the zone of proximal development, which is

the distance between the actual developmental level as determined by independent problem solving and the level of potential development as determined through problem solving under adult guidance or in collaboration with more capable peers. (Vygotsky 1978: 86)

At the stage of other-regulation, L2 gamers (or L2 users in the game context) rely more on proficient speakers of the target language and/or experienced L2 
gamers' assistance to communicate, explore, make meaning and act within the game's social and cultural setting. The dialogic interactions between a novice and an expert at this stage of L2 development can provide sufficient scaffolding for an L2 user to make progress and reach the stage of self-regulation via benefiting from more proficient L2 users' feedback on his/her use of the target language in an authentically contextualized setting. At this stage of development, individuals 'have internalized external forms of mediation for the execution or completion of a task' (Lantolf, Thorne and Poehner 2015: 209). As in any other social setting (real or virtual), in which semiotically mediated social interactions take place at different levels of complexity, communicating within the world of MMOGs can arguably provide opportunities for L2 users to experience the processes of L2 development through gaining more competencies to think and act independently as they grow more proficient in using mediational resources available in the game environment.

Revisiting the concept of Bruner's scaffolding theory, Beed, Hawkins and Roller (1991) and Wood and Wood (1996) underlined the most essential features of scaffolding that facilitate the internalization of new knowledge and skills by the learner. These features include collaborative interaction between a novice and an expert, adjustable level of support and guidance provided by taking the learner's zone of proximal development into account and temporal support and guidance that dwindle away to nothing depending on the learner's progress towards self-reliance or independence. Researchers (e.g. Lee 2008; Peterson 2010a, 2012b) have widely acknowledged that all three essential features of scaffolding exist when L2 learners join in-game communities and play the game with more proficient L2 users (either native or non-native speakers) and/or more senior members. By drawing on the concept of scaffolding and zone of proximal development, SLA scholars can further investigate how and to what extent collaborative and supportive interactions between an L2 learner and more proficient L2 users can help the learner internalize and develop syntactic, semantic and pragmatic aspects of the target language in the context of MMOGs.

Within the framework of SCT, learning results primarily from social interactions 'in cultural, linguistic, and historically formed settings such as family life, peer group interaction, and institutional contexts like schooling, organized social activities, and workplaces' (Lantolf, Thorne and Poehner 2015: 207). With such emphasis on an individual's participation in and interaction with one's social setting, the construct of intersubjectivity also becomes central when SCT guides research. Intersubjectivity refers to the state of shared meaning (e.g. of social and cultural phenomena) that is achieved collaboratively and 
drawn upon by two or more interactants as a common conceptual ground for subjective interpretation of reality (Jenks 2012). To co-construct meaning and achieve intersubjectivity throughout their interactions, individuals get involved in an array of different activities such as turn-taking, negotiation of meaning, self- and other-corrections and giving and receiving feedback. Based on SCT, these activities allow the interactants' cognitively and socially scaffolded development (Lantolf and Thorne 2006). According to Jenks (2012), studying intersubjectivity can take two different research trajectories: to study how interactants resolve troubles or communication breakdown in dialogues and how they maintain intersubjectivity when there is no apparent communication problem in interactions. Aligned with these domains of inquiry is the study of the opportunities for L2 development from the interactionist perspective on SLA (Pica 1994; Gass 1997).

\section{Interactionist perspective on SLA}

Interaction in the target language has widely been identified as playing a crucial role in language learning. Peterson (2010a) outlined two different but overlapping accounts drawn from the interactionist perspective on second language development: sociocultural and psycholinguistic. The sociocultural account looks into the developmental processes an L2 learner undergoes to move from a total reliance on objects and others towards self-reliance in using L2 to co-construct meaning. The psycholinguistic account highlights the roles that negotiations of meaning and negotiations of form play in promoting opportunities for L2 development. In line with this account of the interactionist perspective are Egbert, Chao and Hanson-Smith's (1999) four optimal environmental conditions for L2 learning. They include the conditions in which learners 'have opportunities to interact and negotiate meaning, 'are exposed to and encouraged to produce varied and creative language', 'have enough time and feedback' and 'are guided to attend mindfully to the learning process' (Egbert, Chao and Hanson-Smith 1999: 4).

Many scholars who have adopted this theoretical perspective to examine the phenomenon of SLA have underlined the significance of negotiations of meaning and form as well as interactional modifications in second language development (e.g. Long 1983, 1985; Long and Porter 1985; Porter 1986; Pica et al. 1989). From this theoretical lens, 'negotiation for meaning, and especially negotiation work that triggers interactional adjustments by the NS or more competent interlocutor, 
facilitates acquisition because it connects input, internal learner capacities, particularly selective attention, and output in productive ways' (Long 1996: 4512). Long's Interaction Hypothesis incorporates many notions underlying other theories, for example, Krashen's (1985) Input Hypothesis, Swain's (1985) pushed output hypothesis and Schmidt's (1990) noticing hypothesis. Long's Interaction Hypothesis lists the occurrence of three most important conditions claimed to be facilitative in the process of L2 development. They include comprehension of L2 input, production of modified output (prompted by either form-focused negotiation work or corrective feedbark) and attention to L2 form (or noticing the gap in one's interlanguage).

According to Krashen's Input Hypothesis, the necessary condition for the language 'acquisition' process to operate is being exposed to rich comprehensible L2 input provided hr sither other L2 users or the context in which conversational exchang ke place. According to Krashen, this comprehensible input needs to be slightly, that is, $i+1$, beyond the learner's current L2 linguistic competence. Krashen distinguished between unconscious 'acquisition' and conscious 'learning' processes and claimed that successful SLA is largely the outcome of unconscious processes. Krashen's 'unconscious acquisition' corresponds to the concepts of 'incidental learning' and 'socialisation or tacit learning' suggested by Schugurensky (2007 cited in Sockett 2014). According to Shugurensky, a learner gets involved in 'incidental learning' when s/he does not have the intention to learn but is aware that learning is taking place. During 'socialisation or tacit learning' neither a learner's deliberate intention nor his or her awareness is involved. In other words, 'socialisation or tacit learning is an almost natural assimilation of values, attitudes, behaviour, skills and knowledge which occurs in everyday life' (Sockett 2014: 10). Long's interaction hypothesis underlines the significance of comprehensible input in the process of L2 development. Contrary to Krashen, Long believes in the impact of the input that is made comprehensible through interactional modifications during negotiations of meaning (when communication problems arise) (Ellis 1994). As Scarcella and Higa (1981) maintained, this adjusted input is 'optimal' and more impactful in the process of SLA as it develops from negotiation work that involves the learner's noticing the gap in his or her interlanguage.

According to Swain's (1985) output hypothesis, being pushed - beyond one's repertoire of linguistic knowledge - to produce comprehensible output is crucial in the process of L2 development. Swain (1995) emphasized the role of attention to and awareness of output. In this regard, Swain and Lapkin contended, 
In producing the L2, a learner will on occasion become aware of (i.e., notice) a linguistic problem (brought to his/her attention either by external feedback (e.g., clarification requests or internal feedback). Noticing a problem 'pushes' the learner to modify his/her output. In doing so, the learner may sometimes be forced into a more syntactic processing mode than might occur in comprehension. (1995: 373)

Another related notion to Long's interactionist perspective to SLA is Schmidt's (1990) noticing hypothesis. According to this hypothesis, learning is impossible without attention and 'awareness'; that is, for input to become intake for learning, it needs to be noticed first by the learner. Unlike Krashen, who believes in the superiority of unconscious acquisition process over conscious processes of learning, many researchers (e.g. Gass 1988; Robinson 1995) agree that a learner needs to consciously $\square \quad 1$ to and 'notice' linguistic form (i.e. grammar, syntax, pronunciation, etc.) cquisition.

The optimal conditions for L2 development from the interactionist perspective have been widely investigated by SLA scholars in computermediated communication (CMC) settings (e.g. van der Zwaard and Bannink 2014, 2016; Kim 2017; Chen and Chiang 2018; Yanguas and Bergin 2018). This line of research, however, has not been pursued rigorously in the context of MMOGs that are considered as highly interactive social settings. MMOG research framed by the principles underlying the interactionist perspective on SLA can raise a variety of solid research questions such as: What types of tasks within the game context can promote more interactions as opportunities for L2 development? How frequently do L2 learners face communication breakdown (i.e. cases of discourse incomprehension) in their interactions (with other L2 learners and more proficient L2 users) during the gameplay? What are the most prominent sources or triggers (e.g. syntactic, semantic, pragmatic) of discourse incomprehension? How often do the interactants get involved in negotiations and, in turn, reconstruction of meaning? What communication strategies (single and multimodal) do the participants in negotiations apply to bridge the communication gaps? To what extent are these negotiations successful? How far do L2 learners notice (and reflect upon) the gaps in their interlanguage when the source(s) of incomprehension are identified and collaboratively negotiated? How different are the patterns of negotiations across different levels of L2 proficiency?

The second domain of research that Jenks (2012) suggested is to study how interactants maintain intersubjectivity when there is no apparent communication problem. Aligned with this domain of research are the studies that conduct micro-interactional analyses to scrutinize the architecture of 
jointly produced discourse that yields it intelligible, comprehensible and easy to follow. Mori and Hayashi (2006), for example, studied how first and second language speakers coordinated vocal and non-vocal (i.e. gestures) resources to achieve and maintain intersubjectivity. They found that the L2 speakers' practice of 'embodied completion' 'not only facilitates comprehension but also triggers an incidental opportunity for the L2 speaker to learn more advanced linguistic forms' (Mori and Hayashi 2006: 196). Inspired by this research trajectory, SLA researchers can investigate how and to what extent L2 speakers coordinate talk and gesture - as a communication strategy - to produce a hybrid discourse that can help them establish shared linguistic and non-linguistic resources to achieve and maintain intersubjectivity. In the context of MMOGs, in particular, SLA research can raise and address interesting questions such as: How do L2 learners and more proficient L2 users co-construct intersubjectivity throughout their embodied (i.e. avatar-mediated) interactions using text and/or voice-based chat channels? What linguistic and non-linguistic (e.g. signs, symbols, colours, shapes, sounds, motions and actions, gestures and postures) semiotic tools are available for the interactants in the game context to co-construct meaning and achieve intersubjectivity? How and under what communication circumstances do the interactants fuse linguistic and non-linguistic resources to engender hybrid moves to achieve, maintain or restore intersubjectivity? Or, how and to what extent do these avatar-embodied (inter)actions help L2 learners develop their communication strategies in the target language? This line of process-oriented (Chapelle 2001) research seeks to reveal the extent to which MMOGs can afford the conditions that are hypothesized - from the interactionist perspective - as facilitative of the processes underlying SLA.

\section{Lave and Wenger's Situated Learning Model}

Sociocultural perspectives on SLA also view language learning as a process that is affected significantly by the social and cultural variables of the context in which learning takes place. As such, closely related to the core constructs of SCT are the concepts that shape Lave and Wenger's situated learning model (Lave and Wenger 1991). Learning in this model is viewed as a situated activity and is characterized as a process termed by Lave and Wenger as legitimate peripheral participation. Mastery of knowledge and skill happens as individuals participate in the sociocultural practices of a community as peripheral members and gradually advance toward becoming core members of the community. In 
Lave and Wenger's situated learning model, there are two primary constructs, situated learning and communities of practice, which will be elaborated and linked to the dynamics of interaction and communication in the context of MMOGs.

Lave and Wenger's situated learning model posits that learning takes place in its non-educational form as an individual is involved in performing meaningful tasks that are authentically situated in social and cultural contexts. From this perspective, learning is experienced, and meaning is co-constructed, as an individual is involved in jointly sharing and developing practices within a community of practice (Lave and Wenger 1991). Lave and Wenger's situated learning model is aligned with two of Egbert, Chao and Hanson-Smith's (1999: 4) conditions for optimal language learning environments: 'Learners interact in the target language with an authentic audience', and 'learners are involved in authentic tasks'. The notion of situated learning is also reflected in some of Gee's (2003) learning principles in video games, for example, situated meaning principle and text principle. According to the situated meaning principle, 'the meanings of signs (words, actions, objects, artifacts, symbols, texts, etc.) are situated in embodied experience. Meanings are not general or decontextualized. Whatever generality meanings come to have is discovered bottom up via embodied experiences' (Gee 2003: 108). According to the text principle, 'texts are not understood purely verbally ... but are understood in terms of embodied experiences. Learners move back and forth between texts and embodied experiences' (Gee 2003: 108).

In order to achieve higher-level goals in MMOGs, L2 learners (like any other gamers) have to collaborate with other players (represented in games by embodied avatars) - in small or large teams - to undertake goal-oriented and meaningful tasks using the medium of language that is authentically contextualized. In such contexts, L2 is utilized as a prominent medium - in its text or voice forms - to co-construct, negotiate and communicate meaning in an authentic setting as in any other everyday life communication setting (Thorne and Fischer 2012). According to Lave and Wenger's (1991) situated learning theory, learning takes place within communities of practice characterized by joint enterprise, mutual engagement and shared repertoire of communal resources (Wenger 1998). In other words, learning - as a socially and culturally situated phenomenon - takes place informally as an individual gets progressively involved in interactions with more experienced (or senior) members in a community of practice. Eckert and McConnell-Ginet (1992: 464) defined a community of practice as 'an aggregate of people who come together around mutual engagement in an endeavor. Ways 
of doing things, ways of talking, beliefs, values, power relations - in short, practices emerge in the course of this mutual endeavor.'

The same learning conditions prevail within the communities of practice formed and evolved in (e.g. guilds) and out (e.g. community forum sites and game-external websites) of MMOGs environments. These communities are composed of like-minded game players who bond together, sometimes for years, to share and build on each other's knowledge and experience, to collaborate and accomplish in-game goals, to create and develop their virtual identities and contribute to their communities as committed virtual citizens. In the case of social media in its general sense and MMOGs in particular, joint enterprise or shared domain of interests implies that MMOG online communities are organized on the basis of common interests and shared goals. All users who are identified by their communities seek to communicate their thoughts and share their knowledge with other members of their group. More clearly, online communities develop around goals, interests, concepts and values that matter to each and every one of their members. As another essential characteristic of every community, mutual engagement suggests that MMOG players are constantly engaged in meaningful collaborations to accomplish a set of collective goals. Gamers share and discuss ideas in game-related forums. They invite people to join their networks and participate in a multitude of different activities and social events. These meaningful mutual engagements involve shared meaning-making efforts that are constantly contributing to a user's socio-pragmatic awareness (Blattner and Fiori 2011) and sociocultural learning (McBride 2009). The shared repertoire of communal resources is developed by communities over a period of collaboration and participation. In the case of MMOG online communities, shared repertoire of communal resources refers to a vast repertoire of resources that are constantly shared and developed within communities of gamers. These resources include a wide range of communal assets such as a system of trust and commitment, a set of accumulated technical knowledge and skills, a repertoire of well-discussed ideas and sensibilities as well as cultural and social artefacts (Thorne, Black and Sykes 2009).

Related to the notion of community of practice is the concept of affinity group, defined as 'a group that is bonded primarily through shared endeavors, goals, and practices and not shared race, gender, nation, ethnicity, or culture' (Gee 2003: 197). The close examination of online gaming affinity spaces (Gee 2003, 2007), which emerge and evolve within the socially dynamic and interactive world of MMOGs, can provide rich insights for SLA scholars who seek to find out how and to what extent the social structure, cultural characteristics and 
psychological dynamics of such environments contribute to their affordances as potential venues for practicing and developing L2 skills. For example, Mitchell, Myles and Marsden (2013: 270) contended that 'the social structure of communities [of practice] and the power relations obtaining within them define the learning possibilities available to members'. By drawing on this claim, many research questions can be formulated with regard to the context of MMOGs. To name a few, the questions include the following: What characterizes an optimum social structure of a community of practice that can help to create an environment with ample L2 learning opportunities? What is the dynamic (social, cultural and psychological) of power relations - particularly between novice and expert MMOG players - that creates a favourable condition for L2 development? How are novice members of a community of practice received as legitimate peripheral participants? How do the newcomers gradually inculcate the social and cultural norms of the community and become core members? How significant is the role of $\mathrm{L} 2$ - as a prominent semiotic medium of communication - in exploring, negotiating and instilling the community's norms and values? Plenty of other research questions can be raised by SLA researchers who seek to explore the social, cultural and psychological dynamics of MMOG communities and find out how such dynamics can contribute to the affordances of these communities for providing a promising environment for L2 learning and socialization.

\section{Conclusion}

MMOGs have recently attracted the attention of SLA scholars, who seek to explore the potential of these virtual social settings for second language learning and pedagogy. Although research in this area is still in an embryonic stage of development, SLA scholars have come up with some promising findings regarding the affordances of these online social contexts for L2 learning and L2 socialization. Reviews, however, suggest that research in this area needs to improve in terms of the theoretical framework(s) underlying its design and hypotheses. This chapter seeks to underscore the significance and implications of theory in constructing solid research questions. This chapter sought to set an example of how the underlying constructs of some relevant theoretical frameworks can inform SLA researchers who are interested in studying MMOGs as potential venues for L2 development. To this end, it focused on SCT and its key underlying constructs to provide some insights into SLA research 
in the context of MMOGs. SCT is taken up as the point of reference as it is the most prevalently adopted (or at least referred to) in the current literature on MMOG-enhanced L2 learning and pedagogy. The key concepts in SCT are then linked to some other relevant theoretical constructs that originated from the interactionist perspective to SLA. As implied in this chapter, the processes underlying SLA in the context of MMOGs can be theorized and explained by drawing on various related theoretical constructs that come from different theoretical sources. In other words, to capture a wider range of perspectives (e.g. sociocultural, sociolinguistic and psycholinguistic) on SLA in the context of MMOGs, researchers have to draw on a broader range of theoretical frameworks from different primary sources such as linguistics, sociology, psychology and anthropology. It is hoped that research in this area evolves to become more rigorous through being designed and conducted based on an ensemble of relevant theoretical frameworks.

\section{References}

Beed, P. L., E. M. Hawkins and C. M. Roller (1991), 'Moving Learners toward Independence: The Power of Scaffolded Instruction', The Reading Teacher 44 (9): 648-55.

Blattner, G., and M. Fiori (2011), 'Virtual Social Network Communities: An Investigation of Language Learners' Development of Sociopragmatic Awareness and Multiliteracy Skills', CALICO Journal 29 (1): 24-43.

Bytheway, J. (2014), 'In-Game Culture Affects Learners' Use of Vocabulary Learning Strategies in Massively Multiplayer Online Role-Playing Games', International Journal of Computer-Assisted Language Learning and Teaching 4 (4): 1-13.

Chapelle, C. A. (2001), Computer Applications in Second Language Acquisition: Foundations for Teaching, Testing, and Research, Cambridge: Cambridge University Press.

Chen, J., and C. Chiang (2018), 'The Interplay of Tasks, Strategies and Negotiations in Second Life', Computer Assisted Language Learning 31 (8): 960-86.

Cornillie, F., S. L. Thorne and P. Desmet (2012), 'ReCALL Special Issue: Digital Games for Language Learning: Challenges and Opportunities: Editorial Digital Games for Language Learning: From Hype to Insight?', ReCALL 24 (3): 243-56.

Eckert, P., and S. McConnell-Ginet (1992), 'Think Practically and Look Locally: Language and Gender as Community-Based Practice', Annual Review of Anthropology 21 (1): 461-90.

Egbert, J., C.-C. Chao and E. Hanson-Smith (1999), 'Computer-Enhanced Language Learning Environments: An Overview', in J. Egbert and E. Hanson-Smith 
(eds), CALL Environments: Research, Practice, and Critical Issues, 1-13, Alexandria: Teachers of English to Speakers of Other Languages.

Ellis, R. (1994), The Study of Second Language Acquisition, Oxford: Oxford University Press.

Ellis, R. (2016), 'Focus on Form: A Critical Review', Language Teaching Research 20

(3): 405-28.

Fuster, H., A. Chamarro, X. Carbonell and R. J. Vallerand (2014), 'Relationship between Passion and Motivation for Gaming in Players of Massively Multiplayer Online Role-Playing Games', Cyberpsychology, Behavior, and Social Networking 17 (5): 292-7.

Gass, S. M. (1988), 'Integrating Research Areas: A Framework for Second Language Studies', Applied Linguistics 9 (2): 198-217.

Gass, S. M. (1997), Input, Interaction, and the Second Language Learner, Mahwah, NJ: Erlbaum.

Gee, J. P. (2003), What Video Games Have to Teach Us about Learning and Literacy,

New York: Palgrave Macmillan.

Gee, J. P. (2007), Good Video Games and Good Learning: Collected Essays on Video Games, Learning and Literacy, New York: Peter Lang.

Godwin-Jones, R. (2014), 'Emerging Technologies Games in Language Learning: Opportunities and Challenges', Language Learning \& Technology 18 (2): 9-19.

Jabbari, N., and Z. R. Eslami (2019), 'Second Language Learning in the Context of Massively Multiplayer Online Games: A Scoping Review', ReCALL 31 (1): 92-113. Jenks, C. (2012), 'Analysis of Dialogue', in C. Chapelle (ed.), The Encyclopedia of Applied Linguistics, 64-9, Oxford: Blackwell.

Kaplan, A. M., and M. Haenlein (2010), 'Users of the World, Unite! The Challenges and Opportunities of Social Media', Business Horizons 53 (1): 59-68.

Ke, F. (2009), 'A Qualitative Meta-Analysis of Computer Games as Learning Tools', in

R. E. Ferdig (ed.), Handbook of Research on Effective Electronic Gaming in Education, 1-32, Hershey, PA: IGI Global.

Kim, N.-Y. (2017), 'Effects of Types of Voice-Based Chat on EFL Students' Negotiation of Meaning According to Proficiency Levels', English Teaching 72 (1): 159-81.

Krashen, S. D. (1985), The Input Hypothesis: Issues and Implications, London: Longman. Lantolf, J. P., and S. L. Thorne (2006), Sociocultural Theory and the Genesis of Second Language Development, Oxford: Oxford University Press.

Lantolf, J. P., S. L. Thorne and M. E. Poehner (2015), 'Sociocultural Theory and Second Language Development', in B. van Patten and J. Williams (eds), Theories in Second Language Acquisition, 207-26, New York: Routledge.

Lave, J., and E. Wenger (1991), Situated Learning: Legitimate Peripheral Participation, Cambridge: Cambridge University Press.

Lee, L. (2008), 'Focus-on-Form through Collaborative Scaffolding in Expert-to-Novice Online Interaction', Language Learning \& Technology 12 (3): 53-72. 
Long, M. H. (1981), 'Input, Interaction, and Second Language Acquisition', Annals of the New York Academy of Sciences 379 (1): 259-78.

Long, M. H. (1983), 'Linguistic and Conversational Adjustments to Non-Native Speakers', Studies in Second Language Acquisition 5 (2): 177-93.

Long, M. H. (1985), 'Input and Second Language Acquisition Theory', in S. M. Gass and C. G. Madden (eds), Input in Second Language Acquisition, 377-93, Rowley, MA: Newbury House.

Long, M. H. (1996), 'The Role of the Linguistic Environment in Second Language Acquisition', in W. C. Ritchie and T. K. Bhatia (eds), Handbook of Second Language Acquisition, 413-68, New York: Academic Press.

Long, M. H., and P. A. Porter. (1985), 'Group Work, Interlanguage Talk, and Second Language Acquisition', TESOL Quarterly 19 (2): 207-25.

Loschky, L., and R. Bley-Vroman (1993), 'Grammar and Task-Based Methodology', in G. Crookes and S. M. Gass (eds), Tasks and Language Learning: Integrating Theory and Practice, 123-67, Clevedon: Multilingual Matters.

McBride, K. (2009), 'Social-Networking Sites in Foreign Language Classes: Opportunities for Re-creation', in L. Lomicka and G. Lord (eds), The Next Generation: Social Networking and Online Collaboration in Foreign Language Learning, 35-58, San Marco, TX: Calico Press.

Mitchell, R., F. Myles and E. Marsden (2013), Second Language Learning Theories, London: Routledge.

Mori, J., and M. Hayashi (2006), 'The Achievement of Intersubjectivity through Embodied Completions: A Study of Interactions between First and Second Language Speakers', Applied Linguistics 27 (2): 195-219.

Neuman, L. W. (2003), Social Research Methods: Qualitative and Quantitative Approaches, Boston, MA: Allyn and Bacon.

Peterson, M. (2010a), 'Massively Multiplayer Online Role-Playing Games as Arenas for Second Language Learning', Computer Assisted Language Learning 23 (5): 429-39.

Peterson, M. (2010b), 'Digital Gaming and Second Language Development: Japanese Learners' Interactions in a MMORPG, Digital Culture \& Education 3 (1): 56-73.

Peterson, M. (2012a), 'EFL Learner Collaborative Interaction in Second Life', ReCALL 24 (1): 20-39.

Peterson, M. (2012b), 'Learner Interaction in a Massively Multiplayer Online Role Playing Game (MMORPG): A Sociocultural Discourse Analysis', ReCALL 24 (3): $361-80$.

Pica, T. (1994), 'Research on Negotiation: What Does It Reveal about SecondLanguage Learning Conditions, Processes, and Outcomes?', Language Learning 44 (3): 493-527.

Pica, T, L. Holliday, N. Lewis, and L. Morgenthaler (1989), 'Comprehensible Output as an Outcome of Linguistic Demands on the Learner', Studies in Second Language Acquisition 11 (1): 63-90. 
Porter, P. (1986), 'How Learners Talk to Each Other: Input and Interaction in TaskCentered Discussions', in R. R. Day (ed.), Talking to Learn: Conversation in Second Language Acquisition, 200-22, Rowley, MA: Newbury House.

Przybylski, A. K., R. M. Ryan and C. S. Rigby (2009), 'The Motivating Role of Violence in Video Games', Personality and Social Psychology Bulletin 35 (2): 243-59.

Reinders, H., and S. Wattana (2015), 'The Effects of Digital Game Play on Second Language Interaction', International Journal of Computer-Assisted Language Learning and Teaching 5 (1): 1-21.

Reinhardt, J. (2019), Gameful Second and Foreign Language Teaching and Learning: Theory, Research, and Practice, Switzerland: Springer Nature.

Reinhardt, J., and J. M. Sykes (2012), 'Conceptualizing Digital Game-Mediated L2 Learning and Pedagogy: Game-Enhanced and Game-Based Research and Practice', in H. Reinders (ed.), Digital Games in Language Learning and Teaching, 32-49, Basingstoke: Palgrave Macmillan.

Robinson, P. (1995), 'Attention, Memory and the "Noticing" Hypothesis', Language Learning 45 (2): 285-331.

Scarcella, R. C., and C. Higa (1981), 'Input, Negotiation and Age Differences in Second Language Acquisition', Language Learning 31 (2): 409-34.

Schmidt, R. W. (1990), 'The Role of Consciousness in Second Language Learning', Applied Linguistics 11 (2): 129-58.

Schugurensky, D. (2007), 'Vingt mille lieues sous les mers: Les quatre défis de l'apprentissage informel', Revue Française de Pédagogie 3 (160): 13-27.

Sockett, G. (2014), The Online Informal Learning of English, Basingstoke: Palgrave Macmillan.

Spolsky, B. (1989), Conditions for Second Language Learning: Introduction to a General Theory, Oxford: Oxford University Press.

Swain, M. (1985), 'Communicative Competence: Some Roles of Comprehensible Input and Comprehensible Output in its Development', in S. M. Gass and C. G. Madden (eds), Input in Second Language Acquisition, 235-53, Rowley, MA: Newbury House. Swain, M. (1995), 'Three Functions of Output in Second Language Learning', in M. Swain, G. Cook and B. Seidlhoffer (eds), Principle and Practice in Applied Linguistics: Studies in Honor of H. G. Widdowson, 125-44, Oxford: Oxford University Press.

Swain, M., and S. Lapkin (1995), 'Problems in Output and the Cognitive Processes They Generate: A Step towards Second Language Learning', Applied linguistics 16 (3): 371-91.

Thorne, S. L., and I. Fischer (2012), 'Online Gaming as Sociable Media', Alsic. Apprentissage des Langues et Systèmes d'Information et de Communication 15 (1): $1-25$.

Thorne, S. L., I. Fischer and X. Lu (2012), 'The Semiotic Ecology and Linguistic Complexity of an Online Game World', ReCALL 24 (3): 279-301. 
Thorne, S. L., R. W. Black and J. M. Sykes (2009), 'Second Language Use, Socialization, and Learning in Internet Interest Communities and Online Gaming', Modern Language Journal 93 (1): 802-21.

van der Zwaard, R., and A. Bannink (2014), 'Video Call or Chat? Negotiation of Meaning and Issues of Face in Telecollaboration', System 44: 137-48.

van der Zwaard, R., and A. Bannink.(2016), 'Nonoccurrence of Negotiation of Meaning in Task-Based Synchronous Computer-Mediated Communication', Modern Language Journal 100 (3): 625-40.

Vygotsky, L. S. (1978), Mind in Society: The Development of Higher Psychological Processes, Cambridge, MA: Harvard University Press.

Vygotsky, L. S. (1981), 'The Instrumental Method in Psychology', in J. V. Wertsch (ed.), The Concept of Activity in Soviet Psychology, 134-43, Armonk, NY: M. E. Sharpe.

Wenger, E. (1998), Communities of Practice: Learning, Meaning, and Identity, New York: Cambridge University Press.

Whitton, N. (2014), Digital Games and Learning: Research and Theory, London: Routledge.

Woo, Y., and T. C. Reeves (2007). 'Meaningful Interaction in Web-Based Learning: A Social Constructivist Interpretation', Internet and Higher Education 10 (1): 15-25.

Wood, D, and H. Wood (1996), 'Vygotsky, Tutoring and Learning', Oxford Review of Education 22 (1): 5-16.

Wu, W.-H., W.-B. Chiou, H.-Y. Kao, C.-Hsing A. Hu and S.-H. Huang (2012), 'Re-exploring Game-Assisted Learning Research: The Perspective of Learning Theoretical Bases', Computers \& Education 59 (4): 1153-61.

Yanguas, I., and T. Bergin (2018), 'Focus on Form in Task-Based L2 Oral ComputerMediated Communication', Language Learning \& Technology 22 (3): 65-81. 
